\title{
Predictors of loss to follow up among adult clients attending antiretroviral treatment at Karamara general hospital, Jigjiga town, Eastern Ethiopia, 2015: a retrospective cohort study
}

\author{
Wubareg Seifü ${ }^{1 *}$, Walid Ali $^{2}$ and Beyene Meresa ${ }^{3}$
}

\begin{abstract}
Background: Retention in care and adherence to the treatment is very important for the success of the program while access for treatment is being scaled up. Without more precise data about the rate of loss to follow up as well the characteristics of those who disengage from the treatment appropriate interventions to increase ART adherence cannot be designed and implemented. Therefore the aim of this study was to determine incidence and predictors of loss to follow up among adult ART clients attending in Karamara Hospital, Jigjiga town, Eastern Ethiopia, 2015.

Methods: An institutional based retrospective cohort study were undertaken among 1439 adult people living with HIV/AIDS and attending ART clinic between September 1, 2007 and September 1, 2014 at Karamara Hospital was undertaken. Loss to follow up was defined as not taking an ART refill for a period of 90 days or longer from the last attendance for refill and not yet classified as 'dead' or 'transferred-out'. A Kaplan-Meier model was used to estimate rate of time to loss to follow up and Cox proportional hazards modeling was used to identify predictors of loss to follow up among ART clients.

Result: Of 1439 patients, 830(58.0\%) were females in their sex. The mean age of the cohort was 33.5 years with a standard deviation of 9.33. Around 213 (14.8\%) patients were defined as LTFU. The incidence rate of loss to follow up in the cohort was $26.6 \%(95 \% \mathrm{Cl}$; $18.1-29.6)$ per 100 person months. Patients with male sex [HR: $2.1 \mathrm{Cl} ;(1.3-3.4)]$, patients whose next appointment weren't recorded [HR: 1.2, 95\% Cl; (1.12-1.36)] and patients who did not disclose their status to any one [HR: $2.8,95 \% \mathrm{Cl} ;(2.22-5.23)]$ were significantly associated with LTFU in the cox proportional model. Conclusion: Overall, these data suggested that LTFU in this study was high. The ART patients' next appointment should be documented very well and as well the clients should be advised to adhere with treatment program as per the schedule. Defaulter tracing mechanism should be operational and strengthen in the health facility. Effective control measures should be designed for at-risk population such as male patients.
\end{abstract}

Keywords: Loss to follow up, ART, Jigjiga town, Predictors, Eastern Ethiopia

\footnotetext{
* Correspondence: wub2003@gmail.com

${ }^{1}$ College of Medicine and Health Sciences, Public Health department,

Epidemiology and Biostatistics Unit, Jigjiga University, P.O. Box:1020, Jigjiga,

Ethiopia

Full list of author information is available at the end of the article
}

(c) The Author(s). 2018 Open Access This article is distributed under the terms of the Creative Commons Attribution 4.0 International License (http://creativecommons.org/licenses/by/4.0/), which permits unrestricted use, distribution, and reproduction in any medium, provided you give appropriate credit to the original author(s) and the source, provide a link to the Creative Commons license, and indicate if changes were made. The Creative Commons Public Domain Dedication waiver (http://creativecommons.org/publicdomain/zero/1.0/) applies to the data made available in this article, unless otherwise stated. 


\section{Background}

The rapid expansion on the utilization of antiretroviral therapy (ART) has transformed national Acquired Immune Deficiency Syndrome (AIDS) responses and as well contributed significant impact on the health of people living with human immunodeficiency virus (PLWHIV) [1]. The ART treatment has shown promising results in the reduction of HIV transmission and HIV/ AIDS related morbidity and mortality. According to World Health Organization (WHO) report, ART has prevented an estimated 4.2 million deaths in Low and Middle Income Countries (LMICs) in the year 2013 [1].

At the beginning, most of the efforts to combat the AIDS epidemic were mainly focused on access to antiretroviral drugs. Patient adherence to the treatment and retention in care emerged as a critical concern for the health sector to gain the desired outcome of combined ART treatment regimen [1]. Loss to follow-up (LTFU) of clients from ART negatively impacts on the immunological benefits of ART, increase AIDS related morbidity, mortality and hospitalization. LTFU of patients from ART can result serious consequences such as discontinuation of treatment, drug toxicity, treatment failure due to poor adherence, and drug resistance [2-7].

Retention of patients in long term treatment programs has not given due attention since most large scale treatment providers have limited resources to trace missing patients. As a result much attention has focused on patient day-to-day adherence to antiretroviral treatment [4, 7-9]. Lost to follow up patients cannot easily reached out in most of the cases, because patients involved in such situation have decided to be out of care, either voluntarily or involuntarily. Providers typically do not know whether a lost patient has died, transferred to a new treatment site, unable to stay in care due to medical, economical, social or psychological barriers or simply chosen to discontinue their follow up [10].

Even though, Ethiopia has a 1.9\% national HIV/AIDS prevalence $[2,11]$, the magnitude and predictors of LTFU after initiation of antiretroviral therapy are not well documented in most regions of the country. Without more precise data about the rate of loss to follow up as well as the characteristics of those who withdraw from the treatment appropriate interventions to increase ART adherence cannot be designed and implemented. Therefore, evidence based interventions that prevent LTFU in resource limited settings like Ethiopia will improve treatment outcomes and adherence in a cost effective approach.

\section{Methods}

\section{Study setting}

The study was conducted in Jigjiga town which is located at $638 \mathrm{Km}$ from the capital city Addis Ababa.
The total of population of the study area was 199, 756 according to 2007 census [2]. There were five governmental health institutions ( 3 health centers and 2 Hospitals) which provide ART service for the town and surrounding population. All diagnosed HIV positive individuals from VCT, PMTCT or inpatient services were sent to the ART center and registered. If they were eligible to start ART, a unique ART number was given to each patient. Once diagnosed with HIV/AIDS and eligible for ART, patients were provided with ART medication and care free of charge.

\section{Study design and participants}

A retrospective observational cohort study was performed among all adult patients who initiated ART and were followed-up between September 1, 2007 and September 1, 2014 at Karamara General Hospital. All adult patients who initiated ART and were followed-up between September 1, 2007 and September 1, 2014 were included in this study. The study included all cases of lost-to-follow-up from governmental health institution ART clinics during the period of September 2007 to September 2014. Therefore, this was a census type study and didn't involve any sampling. There were 2660 clients' registered for ART service starting from September 2007 to September 2014 at Karamara General Hospital. Patients who were initiated on ART between the periods of September 2007 to September 2014 at karamara General Hospital were the source population for this study. All adult (18 years and above), non-pregnant, AIDS patients in the treatment program from September 2007 through September 2014 were eligible for the study. Patients were excluded if ART initiation or termination date was missing, and/or if dates were wrongly recorded such as, ART initiation date after ART termination date. As well all patients whose deaths were recorded on the medical files and patients who were started on ART but were transferred out to other health facility were excluded from the study.

\section{Measurement}

The data for this research was secondary data collected routinely in the hospital for clinical monitoring and evaluation purposes and entered in an ART database during the follow-up time. The primary outcome variable was LTFU from ART follow-up care after initiation of treatment, confirmed by reviewing medical registration at the hospital, noted by ART adherence supporters. Data recording started from the date that patients started regular HIV care in the clinic to confirmation of a final event. All lost to follow up during September 1, 2007 and September 1, 2014 were included in the study. The patients' identification numbers were used to generate the necessary sample from the records of the health 
facility for extracting data. Socio-demographic characteristics, baseline and follow up clinical and laboratory measurement information, and treatment outcomes were abstracted from patients' cards. Data were retrieved from patients' ART card by trained nurses working in the ART Clinic using uniform data abstraction format prepared for the study. Whenever relevant information was missing, the ART electronic database was consulted. The supervisors checked each completed questionnaire and principal investigator monitored the overall quality of the data collection. In this study lost to follow up was defined as if their last date of contact with the ART clinic was $\geq 3$ months before the date of database closure and they were not known to have died or transferred out. Transferred-out was defined as if the patient had moved to another health facility with confirmed written documentation of transfer out. Proper recording was defined as when the health care provider stated the next appointment date and other related information of the ART clients in a written form on their charts. Whereas censored event was defined as at the date of death or transferred out or at the end of the study period.

\section{Data processing and analysis}

Data were cleaned, edited, and entered onto Epidata version 3.2.1 and exported to SPSS windows version 20 and STATA version 10 for further analysis. Descriptive statistics such as median, mean, SDs and percentage were used to investigate the characteristics of the cohort. Person years of follow up were calculated by assessing the date of enrollment for ART and lost follow up or censoring. Survival analysis and the Kaplan-Meier test were used to investigate factors that influence time to loss to follow up. Hazard ratios (HR), with 95\% confidence intervals were used as effect measures. A $p$-value of 0.05 was considered as significant. Kaplan Meier curves were plotted and compared using log rank tests. Ethical approval was obtained from Jigjiga University ethical review board committee. In addition an official support letter was obtained from the medical director of the Hospital and the ART department as well all collected data were kept confidential. While reviewing patients' records, non-personal identifiers such as patients' medical registration number were used to distinguish study participants during data collection. Written informed consent from study participants were not feasible since this was analysis of secondary data retrieved from the patient cards/database which is available in the Hospital. Because of this reason the ethical committee of the university waived written consent from the study participants directly. The hospital database management department had consented each HIV/AIDS patients to use the data for research purpose through confidential way at the time enrolment to the ART program.

\section{Results}

Between September 1, 2007 and September 1, 2014, a total of $2660 \mathrm{HIV/AIDS}$ patients were newly enrolled for HIV care at Karamara General Hospital ART clinic. Of these, 1542 were eligible for this study based on the inclusion criteria. Of the eligible patients, 103 (6.7\%) of adult ART patients were excluded from the study because their charts were incomplete. Out of the remaining 1439 study population, 1226 (85.2\%) were patients who were under active follow-up for their HIV care while the other $213(14.8 \%)$ were lost to follow-up during the ART period (Fig. 1).

\section{Baseline socio-demographic characteristics of the cohort}

In this study a total of 1439 adult patients on ART between September 2007 and 2014 were included in the statistical analysis. These adult ART patients were followed for about 10,755 person-months. Out of the 1439 study participants analyzed in in this study, $830(58.0 \%)$ were females by their sex. By the time of enrollment into HIV/AIDS care, majority 377 (26.2\%) of the study subjects were between 28 and 32 years of age while 275 (19.1\%) were between the age group of 2327 years of age with a mean $( \pm$ SD) age of $33.49( \pm 9.33)$ years. Of the total study population, 680 (47.3\%) were married. With regard to educational status of study participants, $351(37.3 \%)$ of patients completed primary school, followed by 487 (33.8\%) of patients with no education at all. Majority $713(49.5 \%)$ of study participants were Orthodox Christianity by their religion. Just over one quarter 181 (12.6\%) of the study participants enrolled in HIV/AIDS care were lived outside Jigjiga town (Table 1).

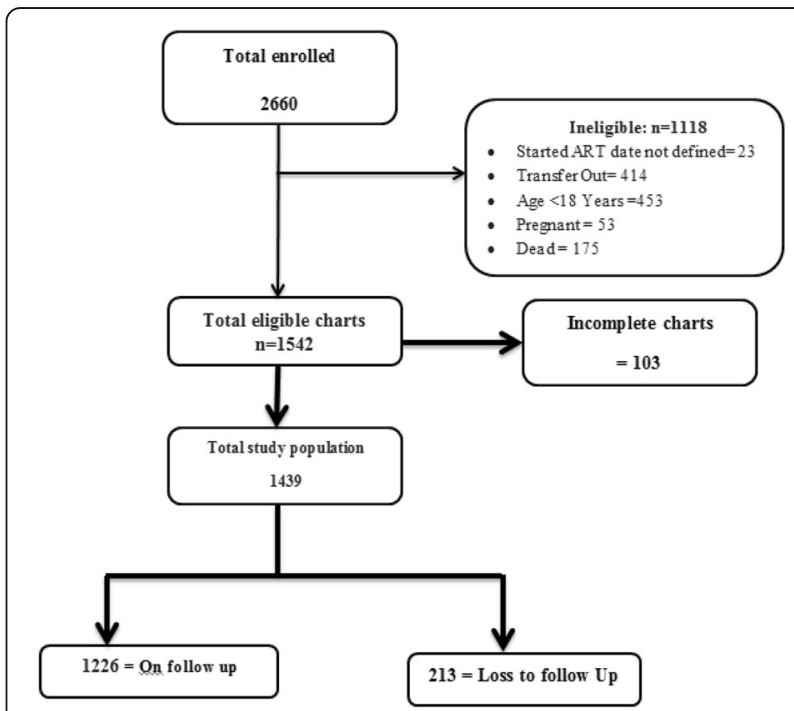

Fig. 1 Profiles of HIV/AIDS clients at Karamara Hospital, Jigjiga (September 1, 2007 to September 1, 2014, Ethiopian Somali Regional State, Eastern Ethiopia; 2015 
Table 1 Baseline socio-demographic characteristics of adult ART patients at Karamara Hospital from September 1, 2007 to September 1, 2014), Somali region, Jigjiga town, Eastern Ethiopia, 2015

\begin{tabular}{|c|c|c|}
\hline Variables & Frequency & Percentage (\%) \\
\hline \multicolumn{3}{|l|}{ Sex } \\
\hline Male & 605 & 42.0 \\
\hline Female & 834 & 58.0 \\
\hline \multicolumn{3}{|l|}{ Religion } \\
\hline Muslim & 658 & 45.7 \\
\hline Orthodox & 713 & 49.5 \\
\hline Protestant & 60 & 4.2 \\
\hline Others & 8 & 0.6 \\
\hline \multicolumn{3}{|l|}{ Marital status } \\
\hline Married & 680 & 47.3 \\
\hline Never married & 211 & 14.7 \\
\hline Divorced & 391 & 27.2 \\
\hline Widowed & 142 & 9.9 \\
\hline Separated & 15 & 1.0 \\
\hline \multicolumn{3}{|l|}{ Age group } \\
\hline $18-22$ & 122 & 8.5 \\
\hline $23-27$ & 275 & 19.1 \\
\hline $28-32$ & 377 & 26.2 \\
\hline $33-37$ & 237 & 16.5 \\
\hline $38-42$ & 204 & 14.2 \\
\hline$>=43$ & 224 & 15.6 \\
\hline \multicolumn{3}{|l|}{ Place of Residence } \\
\hline Jigjiga & 1258 & 87.4 \\
\hline Out of Jigjiga & 181 & 12.6 \\
\hline \multicolumn{3}{|l|}{ Educational status } \\
\hline No education & 487 & 33.8 \\
\hline Primary level & 552 & 38.5 \\
\hline Secondary and above & 388 & 27.0 \\
\hline \multicolumn{3}{|l|}{ Employment status } \\
\hline Government & 205 & 14.2 \\
\hline House wife & 116 & 8.1 \\
\hline Daily laborer & 407 & 28.3 \\
\hline Unemployed & 579 & 40.2 \\
\hline Others & 132 & 9.1 \\
\hline \multicolumn{3}{|l|}{ Contact Person } \\
\hline Yes & 1081 & 75.1 \\
\hline No & 358 & 24.9 \\
\hline
\end{tabular}

Baseline clinical characteristics of the cohort

Among the 1439 patients who had their baseline CD4 cell count documented, 935 (65\%) had CD4 count $\leq 200$ cell $/ \mu$ l while $113(7.9 \%)$ of them had a CD4 count $>350$ cell $/ \mu \mathrm{l}$. The median initial CD4 count was $166 \mathrm{cell} / \mu \mathrm{l}$
$(\mathrm{IQR}=83$ to $233 \mathrm{cell} / \mu \mathrm{l})$. Among the 1439 charts that had complete information about WHO staging, majority $670(46.6 \%)$ of patients were stage III followed by 328 (22.8\%) stage I patients. Among 1439 patient charts that had documentation on past history of tuberculosis, 367 (25.5\%) patients had a history of tuberculosis treatment. Most $811(56.4 \%)$ of the study population have a functional status followed by ambulatory 488 (33.9\%) state whereas most 546 (36.9\%) of the ART clients discloses their status to their family members (Table 2).

\section{The incidence of loss to follow up}

The overall incidence rate of LTFU in the cohort was estimated to be $26.6 \%$ (95\% CI; 18.1-29.6) per 100 person months. Patient retention in care was $14.7 \%$ at

Table 2 Baseline clinical characteristics of adult ART patients at Karamara Hospital from September 1, 2007 to September, 2014, Somali region, Jigjiga town, Eastern Ethiopia, 2015

\begin{tabular}{|c|c|c|}
\hline Variables & Frequency & Percentage (\%) \\
\hline \multicolumn{3}{|l|}{ CD4 cell count/ $\mu \mathrm{l}$} \\
\hline$<=200$ & 935 & 65.0 \\
\hline $201-250$ & 195 & 13.6 \\
\hline $251-300$ & 196 & 13.6 \\
\hline $301-350$ & 113 & 7.9 \\
\hline$>351$ & 113 & 7.9 \\
\hline \multicolumn{3}{|l|}{ WHO stage } \\
\hline Stage I & 328 & 22.8 \\
\hline Stage ॥ & 228 & 15.8 \\
\hline Stage III & 670 & 46.6 \\
\hline Stage IV & 213 & 14.8 \\
\hline \multicolumn{3}{|c|}{ History of TB treatment } \\
\hline Yes & 367 & 25.5 \\
\hline No & 1072 & 74.5 \\
\hline \multicolumn{3}{|c|}{ Next appointment recorded } \\
\hline Yes & 1092 & 75.9 \\
\hline No & 347 & 24.1 \\
\hline \multicolumn{3}{|c|}{ Base line functional status } \\
\hline Functional & 811 & 56.4 \\
\hline Ambulatory & 488 & 33.9 \\
\hline Bed ridden & 140 & 9.7 \\
\hline \multicolumn{3}{|c|}{ ART regimen substitutions } \\
\hline Yes & 172 & 12.0 \\
\hline No & 1267 & 88.0 \\
\hline \multicolumn{3}{|l|}{ Disclosure status } \\
\hline Family members & 546 & 36.9 \\
\hline Spouse only & 453 & 30.6 \\
\hline No one & 358 & 24.2 \\
\hline Relative/friend & 122 & 8.1 \\
\hline
\end{tabular}




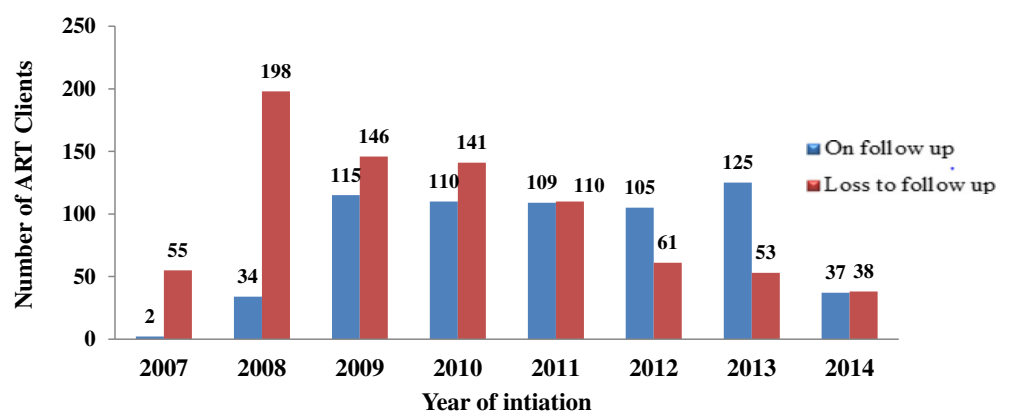

Fig. 2 Number of clients retained and loss to follow up from ART program by each year at Karamara General Hospital, from September 1, 2007 to September, 2014, Ethiopian Somali regional State, Eastern Ethiopia, 2015

2 years and $49.8 \%$ at 5 years in the cohort. Approximately $96.5 \%(55 / 57)$ of the patients that became lost to follow up were lost within the first year of being initiated on ART. The absolute number of patients that were LTFU with each year on ART decreased over time (Fig. 2). The median time on ART before discontinuation of follow-up was 12 months (IQR $=4$ to 16 months). The cumulative incidence of loss to follow up among male ART clients is higher than the female ones (Fig. 3).

\section{Risk factors associated with LTFU among adult ART clients} In the multivariate cox regression model patients with male sex [HR: 2.1CI; (1.3-3.4)], patients whose next appointment were not properly recorded [HR: $1.2,95 \% \mathrm{CI}$; (1.12-1.36)] and patients who did not disclose their status to any one [HR: 2.8, 95\% CI; (2.22-5.23)] were significantly associated with LTFU in the cox proportional hazard model (Table 3).

\section{Discussion}

This study attempted to determine the incidence and predictors of loss to follow up from ART treatment program among adult population. The cumulative incidence of LTFU was $14.8 \%$ among adult ART attendants. In the multivariate analysis being male, next appointment not properly recorded on the medical chart and failed to disclose HIV/AIDS status to any one were the independent predictors of loss to follow up among adults aged 18 years and above.

The overall incidence rate of loss to follow up was $14.8 \%$ in this study. This finding is lower than studies conducted in Sub Saharan countries (20-40\%) [12, 13] but similar to analogous studies done in Northwest Ethiopia, Bahrdar Feleg Hiwot Hospital and Gonder Referral Hospital which showed that the lost to follow up rate were 8.4, 18 and 19\% respectively [14-16].

Generally we had found a progressive decrease in the incidence of LTFU patients with each year after initiation of ART. The incidence of loss to follow up in our study was found to be 85.3 , and $50.2 \%$ by the end of the 2nd and 5th year respectively. This finding is contrast with other studies finding whereby there is progressive increase in LTFU overtime [17-23]. This difference might be attributed due to decentralization of care from referral centers to primary health care facilities in the study area. Currently the Ethiopian health care delivery approach gives much emphasis for decentralization of ART cares to the lower health facilities. This has been largely attributed to the fact that decentralized clinics tend to be closer to patients homes requiring them to travel less, reducing transport costs and building

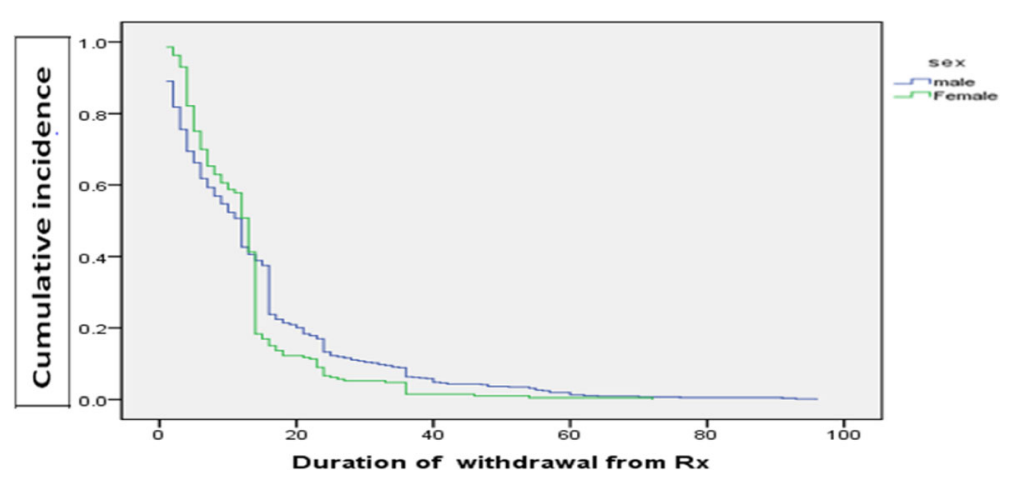

Fig. 3 Kaplan-Meier estimation of cumulative incidence of loss to follow up by sex among adult ART attendants at Karamara Hospital, Jigjiga, Ethiopia, 2015 
Table 3 Cox regression analysis of factors associated with LTFU among adult patients on ART therapy at Karamara General Hospital, September 2007 to September 2014, Somali region, Jigjiga town, Eastern Ethiopia, 2015

\begin{tabular}{|c|c|c|c|c|}
\hline \multirow[t]{2}{*}{ Variables } & \multicolumn{2}{|c|}{ Loss to Follow Up } & \multirow{2}{*}{$\begin{array}{l}\text { AHR } \\
(95 \% \text { Cl) }\end{array}$} & \multirow[t]{2}{*}{$P$ - Value } \\
\hline & Yes & No & & \\
\hline \multicolumn{5}{|l|}{ Sex } \\
\hline Male & $107(34.2)$ & $498(65.8)$ & $2.1(1.3-3.4)$ & $0.034^{*}$ \\
\hline Female & $106(24.7)$ & $728(75.3)$ & 1 & \\
\hline \multicolumn{5}{|c|}{ Next appointment recorded properly } \\
\hline Yes & $190(17.4)$ & $902(82.6)$ & 1 & $0.000^{*}$ \\
\hline No & $23(6.6)$ & $324(93.4)$ & $1.2(1.12-1.36)$ & \\
\hline \multicolumn{5}{|l|}{ History of TB treatment } \\
\hline Yes & $71(19.4)$ & $296(80.6)$ & $1.2(0.08-1.38)$ & \\
\hline No & $142(13.2)$ & $930(86.8)$ & 1 & 0.561 \\
\hline \multicolumn{5}{|l|}{ WHO Stage ${ }^{a}$} \\
\hline । & $38(11.6)$ & $290(88.4)$ & 1 & \\
\hline$\|$ & $29(12.7)$ & $199(87.3)$ & $0.4(0.34-2.34)$ & 0.341 \\
\hline III & $111(16.6)$ & $559(83.4)$ & $0.8(0.40-1.17)$ & 0.123 \\
\hline IV & $35(16.4)$ & $178(83.6)$ & $0.6(0.28-1.43)$ & 0.112 \\
\hline \multicolumn{5}{|l|}{ Functional status $^{\mathrm{b}}$} \\
\hline Functional & $81(10.0)$ & $730(90.0)$ & 1 & \\
\hline Ambulatory & $96(19.6)$ & $392(80.4)$ & $0.73(0.44-1.2)$ & 0.2213 \\
\hline Bed ridden & $36(25.7)$ & $104(74.3)$ & $1.31(0.86-1.9)$ & 0.2364 \\
\hline \multicolumn{5}{|l|}{ CD4 Count } \\
\hline$=<200$ & $152(16.3)$ & $783(83.7)$ & $0.7(0.5-1.0)$ & 0.117 \\
\hline $201-250$ & $21(10.8)$ & $174(89.2)$ & $0.6(0.4-1.8)$ & 0.712 \\
\hline $251-300$ & $16(8.2)$ & $180(91.8)$ & $0.7(0.6-1.0)$ & 0.371 \\
\hline $301-350$ & $10(8.9)$ & $103(91.1)$ & $0.9(1.1-1.8)$ & 0.682 \\
\hline$>=351$ & $14(12.4)$ & $99(87.6)$ & 1 & \\
\hline \multicolumn{5}{|l|}{ Disclosure status } \\
\hline Disclosed to any one & $76(7.0)$ & $1005(93.0)$ & 1 & \\
\hline Not disclosed to any one & $137(38.3)$ & $221(61.7)$ & $2.8(2.22-5.23)$ & $0.034^{*}$ \\
\hline
\end{tabular}

Note

*statistically significant at $p$-value $<0.05$

${ }^{a}$ is based on the clinical sign and symptom complex

${ }^{b}$ Functional = able to perform usual work in or out of the house, harvest, go to school

Ambulatory $=$ able to perform activities of daily living but not able to work or play

Bedridden $=$ not able to perform activities of daily living

stronger links between health services and the community. The closer proximity can also make tracing more feasible from decentralized clinics [24-26]. Additionally the enhancement of community outreach services through several mechanisms, such as involving community health workers, recording detailed information of each patient and expanding the peer outreach program might be the possible reasons for the improvement of retention over time in among the study population.

In this study males were [AHR: $2.195 \%$ CI (1.3-3.4)] found to be at higher risk of LTFU from adult ART treatment programs. This finding is in line with studies conducted in Northwest Ethiopia, Oromia region, and India
$[16,27,28]$. The observed difference might be attributed to variations in the life styles as men spent much time away from their home coupled with high risk of drug abuse might leads to discontinuation from the treatment programs compared to their counter parts. Moreover, most $883(61.4 \%)$ of the study participants enrolled with advanced stage diseases (III \& IV) were males which makes it highly likely that they were lost to follow-up. This finding is consistent with other studies which reported that HIV-infected men seek treatment lately compared to women and are therefore at greater risk of an adverse clinical outcome including death $[29,30]$. Additionally gender based norms imposed by the society where by men is 
considered as the symbol of strength and proud suppress their health care service demands [31, 32]. As a result, they might neglect their weaknesses and susceptibility before achieving the expected level of treatment adherence to ART. This implies that HIV/AIDS treatment response and follow-up mechanism should be gender sensitive in order to prevent loss to follow up.

Study participants without a proper record of the next visit date had a high chance of being LTFU from ART treatment [HR: 1.23, 95\% CI (1.12-1.36)] as compared to their counterparts. This finding was supported by studies which were conducted in Northwest Ethiopia, Malawi and Kenya [33, 16, 34]. This could be because a clinician who failed to record the next appointment date on the patient's chart might also forgot to provide written or verbal information for the patient about the specific date of the next visit and other related messages as well. Hence the probability of return back to the ART clinic for such kind of clients will be unlikely.

Clients who did not disclose their HIV/AIDS status were 1.8 more likely to withdraw from the treatment program as compared to their counterparts [AHR: 2.8, 95\% CI (2.22-5.23)]. This finding is consistent with studies conducted in South Africa and India [35, 36]. This might be attributed that clients will adhere much more if they disclose their status since ART treatment adherence needs comprehensive support and care from different part of the community as well. In this study CD4 count, advanced WHO stage (III/IV) and functional state were not significantly associated with LTFU unlike the findings of studies elsewhere [14-16]. This difference might be due to difference in study setting and study population as well.

This study has some limitations that may impact interpretation of our findings. The first limitation was resulted from the poor tracing and documentation system of patients in the ART program. Patients, who were labeled as LTFU might have been died or self-referred to other facilities. This could have led to an over-estimation of the incidence rate of LTFU in our study The second limitation was missing data with regard to baseline socio-demographic and clinical variables. Following this we only analyzed $54 \%$ of the total ART enrolled clients during the study period and this might under or overestimate the incidence of LTFU in our study. Despite these limitations, we believe that our study findings will provide an important insight into the magnitude and the factors related to LTFU among patients on ART.

\section{Conclusion and recommendations}

The cumulative incidence of loss to follow up among adult population in this study was found $14.8 \%$. Among the socio-demographic factors sex were significantly associated with LTFU among adults ART attendants.
While next appointment recording status and disclosure status were significantly associated with LTFU among the clinical factors. The Hospital ART monitoring and follow up department should strengthen and make the clients tracing system so as to increase client retention in the facility back. On top of this the ART department should record the clients next appointment time and advise them to return back accordingly. Additionally effective control measures should be designed for at-risk population such as male ART clients by ART department of the hospital.

\begin{abstract}
Abbreviations
AHR: Adjusted Hazard Ratio; AIDS: Acquired Immune Deficiency Syndrome; AIDS: Acquired Immune Deficiency Syndrome; ART: Anti-retroviral Therapy; CHR: Crude Hazard Ratio; Cl: Confidence Interval; DRCS: Directorate of Research and Community Service; EDHS: Ethiopian Demographic and Health Survey; FMoH: Federal Minister of Health; HAPCO: HIV/AIDS Prevention and Control Office; HIV: Human Immunodeficiency Virus; HR: Hazard Ratios; IQR: Inter quartile range; LMIC: Low and Middle Income Countries; LTFU: Loss to follow up; PLWHIV: Peoples Living with Human Immunodeficiency Virus; PMTCT: Prevention of Mother to Child Transmission; SD: Standard Deviation; SPSS: Statistical Package for Social Science; SSA: Sub Saharan Africa; VCT: Voluntary Counseling and Testing; WHO: World Health Organization
\end{abstract}

\section{Acknowledgements}

We would like to express our deepest gratitude to Jigjiga University for budgetary support. We are also extremely grateful for data collectors, Karamar Hospital ART department staffs, supervisors and study participants.

\section{Funding}

The budgetary support for this study was covered by Jigjiga University.

\section{Availability of data and materials}

The dataset contains confiential patient data which should not be shared publicly according to the journal ethical policy. Therefore, the datasets used and/or analyzed during the current study are available from the corresponding author and can be shared on reasonable request.

\section{Author's contributions}

WS conceived and designed the study, performed analysis and interpretation of data and drafted the first manuscript. WA and BM participated in data collection, data entry and critical review of the subsequent draft of the manuscript. All authors read and approved the final version of the manuscript for publication.

\section{Authors information}

WS; Lecturer of Epidemiology and Biostatistics, Head of Public Health department, College of Medicine and Health Sciences, Jigjiga University, Jigjiga Town, Eastern Ethiopia; WA; Saint Paul's Hospital Millennium Medical College, Department of Radiology, Addis Ababa, Ethiopia; BM. School of Public Health, College of Health Sciences, Mekelle University, Mekelle, Ethiopia.

\section{Ethical approval and consent to participate}

Approved by the ethical review board of Jigjiga University, College Medicine and Health Sciences. An official support letter was obtained from the medical director of the Hospital and the ART department as well. Written informed consent from study participants were not feasible since this was analysis of secondary data retrieved from the patient cards/database which is available in the Hospital. Because of this reason the ethical committee of the university waived written consent from the study participants directly. The hospital database management department had consented each HIV/AIDS patients to use the data for research purpose through confidential way at the time of enrolment to the ART program. 


\section{Competing interests}

The authors declare that they have no competing interests.

\section{Publisher's Note}

Springer Nature remains neutral with regard to jurisdictional claims in published maps and institutional affiliations.

\section{Author details}

${ }^{1}$ College of Medicine and Health Sciences, Public Health department, Epidemiology and Biostatistics Unit, Jigjiga University, P.O. Box:1020, Jigjiga, Ethiopia. ${ }^{2}$ Department of Radiology, Saint Paul's Hospital Millennium Medical College, Addis Ababa, Ethiopia. ${ }^{3}$ School of Public Health, College of Health Sciences, Mekelle University, Mekelle, Ethiopia.

Received: 22 September 2017 Accepted: 11 June 2018

Published online: 18 June 2018

\section{References}

1. WHO. Global update on HIV treatment: Results, impact and opportunities, 2013. http://www.unaids.org/en/resources/documents/2013/20130630_ treatment report. Accessed 14 Mar 2014.

2. Central Statistics Agency (CSA), "Ethiopian demographic and health survey," Preliminary Report, Central Statistics Agency (CSA), Addis Ababa, Ethiopia, 2011.

3. Assefa Y, Jerene D, Lulseged S, Ooms G, Van Damme W. Rapid scale-up of antiretroviral treatment in Ethiopia: successes and system-wide effects. PLoS Med. 2009;6(4):e1000056

4. Assefa $Y$, Kiflie A, Tesfaye D, et al. Outcomes of antiretroviral treatment program in Ethiopia: retention of patients in care is a major challenge and varies across health facilities. BMC Health Serv Res. 2011;11:81.

5. Abbas UL, Anderson RM, Mellors JW. Potential impact of antiretroviral therapy on HIV transmission and AIDS mortality in resource-limited settings. J Acquir Immune Defic Syndr. 2006:41(5):632-41.

6. García de Olalla P, Knobel H, Carmona A, Guelar A, López-Colomés JL, J a C. Impact of adherence and highly active antiretroviral therapy on survival in HIV-infected patients. J Acquir Immune Defic Syndr. 2002;30(1):105-10.

7. Corey DM, Kim HW, Salazar R, et al. Brief report: effectiveness of combination antiretroviral therapy on survival and opportunistic infections in a developing world setting: an observational cohort study. J Acquir Immune Defic Syndr. 2007:44(4):451-5.

8. Fox MP, Rosen S. Retention of adult patients on antiretroviral therapy in low- and middle- income countries: systematic review and meta-analysis 2008-2013. J Acquir Immune Defic Syndr. 2015;69(1):98-108.

9. Van Damme W, Kober K, Laga M. The real challenges for scaling up ART in sub-Saharan Africa. AIDS. 2006;20(5):653-6.

10. Fox MP, Rosen S. Patient retention in antiretroviral therapy programs up to three years on treatment in sub-Saharan Africa, 2007-2009: systematic review. Trop Med Int Health. 2010;15(Suppl):1-15.

11. MOH-HAPCO: Monthly HIV care and ART update in Ethiopia, January 2009.

12. Rosen S, Fox MP, Gill CJ. Patient retention in antiretroviral therapy programs in sub-Saharan Africa: a systematic review. PLoS Med. 2007:4:e298. [PMC free article] [PubMed]

13. Karcher H, Omondi A, Odera J, Kunz A, Harms G. Risk factors for treatment denial and loss to follow-up in an antiretroviral treatment cohort in Kenya. Tropical Med Int Health. 2007:12:687-94. [PubMed]

14. Wubshet M, Berhane $Y$, et al. High loss to Followup and early mortality create substantial reduction in patient retention at antiretroviral treatment program in north-West Ethiopia. International Scholarly Research Network ISRN AIDS. 2012;2012:1-9.

15. Gugesa, S. Feasibility of using, community outreach workers, to establish ART patient's outcome in Amahara region Ethiopia. Department of epidemiology, University of Washington international training and education center on HIV (I-TECH). 2006

16. Ahmed, et al. Predictors of loss to follow-up before HIV treatment initiation in Northwest Ethiopia: a case control study. BMC Public Health. 2013;13:867.

17. Coetzee D, Hildebrand K, Boulle A, Maartens G, Louis F, et al. Outcomes after two years of providing antiretroviral treatment in Khayelitsha, South Africa. AIDS. 2004;18:887

18. Daniel OJ, Oladapo OT, Ogundahunsi OA, Fagbenro S. Default from antiretroviral treatment programme in sagumu. Nigeria African journal of biomedical research. 2008;11:221-4.
19. Cornell M, Grimsrud A, Fairall L, Fox MP, van Cutsem G, et al. Temporal changes in programme outcomes among adult patients initiating antiretroviral therapy across South Africa, 2002-2007. AIDS. 2010;24:2263-70.

20. Weidle PJ, Malamba S, Mwebaze R, Sozi C, Rukundo G, et al. Assessment of a pilot antiretroviral drug therapy programme in Uganda: patients' response, survival, and drug resistance. Lancet. 2002;360:34-40.

21. Rosen S, Fox MP. Patient retention in antiretroviral therapy programs up to 3 years on treatment in sub-Sahara Africa, 2007-2009: systematic review. Tropical Med Int Health. 2010;15(1):1-15.

22. Cornell M, Grimsrud A, Fairall A, et al. Temporal changes in program outcomes among adult patients initiating antiretroviral therapy across SA, 2002-2007. AIDS. 2010;24(14):2263-70.

23. Forster M, Bailey C, Brinkhof MW, et al. Electronic medical record systems, data quality and loss to follow-up: survey of antiretroviral therapy programs in resource-limited settings. Bull World Health Organ. 2008;86(12):939-47.

24. Central Statistical Agency [Ethiopia] and ICF International: Ethiopia demographic and health survey. Addis Ababa, Ethiopia and Calverton, Maryland, USA: central statistical agency and ICF international; 2012. [Accessed February 25, 2014].

25. Mukora R, Charalambous S, Dahab M, Hamilton R, Karstaedt A. A study of patient attitudes towards decentralization of HV care in an urban clinic in South Africa. BMC Health Serv Res. 2011;11:205.

26. O'Connor C, Oshi R, Jaffer A. Loss to follow-up of stable antiretroviral therapy patients in a decentralized down referral model of care in Johannesburg, South Africa. J Acquir Immune Defic Syndr. 2011;58:429-32.

27. Megerso, et al. Predictors of loss to follow-up in antiretroviral treatment for adult patients in the Oromia region, Ethiopia. HIV/AIDS Research and Palliative Care. 2016:8:83-92.

28. Alvarez-Vria G, Naik PK, Pakaw R, Middle M. Factors associated with attrition, mortality, and loss to follow up after antiretroviral therapy initiation: data from an HIV cohort study in India. Glob Health Action. 2013;6:21682.

29. Yu JK, Chen SC, Wang KY, Chang CS, Makombe SD, Schouten EJ, et al. Et al. true outcomes for patients on antiretroviral therapy who are "lost to followup" in Malawi. Bull World Health Organ. 2007:85:550-4.

30. Bisson GP, Gaolathe T, Gross R, Rollins C, Bellamy S, Mogorosi M, et al Overestimates of survival after HAART: implications for global scale-up efforts. PLoS One. 2008;3:e1725.

31. Braitstein $P$, Boulle A, Nash D, Brinkhof MW, Dabis F, Laurent C, et al. Et al. gender and the use of antiretroviral treatment in resource-constrained settings: findings from a multicenter collaboration. J Women's Health (Larchmt). 2008;17:47-55.

32. Nicastri E, Angeletti C, Palmisano L, Sarmati L, Chiesi A, Geraci A, et al. Et al. gender differences in clinical progression of HIV-1-infected individuals during long-term highly active antiretroviral therapy. AIDS. 2005;19:577-83.

33. Kwong-leung J, Chih-cheng Chen S, et al. True outcome of patients on antiretroviral therapy who are loss to follow up in Malawi. Bulletin of the world health organization. 2007:85(7):501-8.

34. Zachariaha R, Tayler-Smith K, Manzi M, Massaquoi M, Mwagomba B, Griensven J, Engelgem I, Arnould L, Schouten EJ, Chimbwandira FM, Harries AD. Retention and attrition during the preparation phase and after start of antiretroviral treatment in Thyolo, Malawi, and Kibera, Kenya: implications for programs? Trans R Soc Trop Med Hyg. 2011;4191:10.

35. Cardace MM, Ketlhapile M, Heather RS, et al. Why are anti-retroviral treatment patients lost to follow up? A qualitative study from South Africa. Tropical Med Int Health. 2010;15:48-54

36. Lal $\mathrm{V}$, Shashi $\mathrm{K}$, Dewan $\mathrm{R}$, et al. A two-site hospital based study on factors associated with nonadherence to highly active antiretroviral therapy. Indian J Public Health. 2010:54:179-83. 